\title{
风力发电技术发展现状及趋势
}

\author{
李晓明 \\ 辽宁龙源新能源发展有限公司，辽宁沈阳 110000
}

[摘要] 当前, 我国的能源消耗量逐渐增加, 能源紧缺形势逐渐加剧。近年来, 随着国家颁布新能源政策, 风力发电这一清洁 能源逐渐得到电力企业的关注，风力发电技术得到了进步和发展。文中将针对风能发电技术的发展现状进行探究，分析风能 发电技术发展中存在的问题, 并总结风能发电技术水平的发展趋势, 以期为我国风力发电技术的发展提供一定的参考。 [关键词]风力发电; 技术发展; 现状; 趋势

DOI: 10.33142/hst.v3i5.2637 中图分类号: TM614 文献标识码：A

\section{Development Status and Trend of Wind Power Generation Technology}

\author{
LI Xiaoming
}

Liaoning Longyuan New Energy Development Co., Ltd., Shenyang, Liaoning, 110000, China

\begin{abstract}
At present, China's energy consumption is gradually increasing, and the situation of energy shortage is gradually aggravating. In recent years, with the promulgation of new energy policy, wind power generation, a clean energy, has gradually attracted the attention of power enterprises, and wind power technology has been improved and developed. This paper will explore the development status of wind power generation technology, analyze the existing problems in the development of wind power generation technology, and summarize the development trend of wind power generation technology level, in order to provide certain reference for the development of wind power technology in China.
\end{abstract}

Keywords: wind power; technological development; status quo; trend

引言

当前, 随着全球变暖形势的日益恶化, 能源大国纷纷作出承诺并制定了一系列节能减排的目标。我国对于能源问 题高度重视, 提出了一系列有效的节能环保政策, 其中针对新能源发电技术也有相应的指导和要求 ${ }^{[1]}$ 。相对于其他发电 技术而言, 风力发电具有成本较低、设备简单、影响因素较小的优势, 但由于我国风力发电技术起步较晚, 当前的技 术水平与发达国家之间还存在差距 ${ }^{[2]}$ 。因此相关技术研究人员应当针对核心关键技术进行改良, 提高发电设备的先进性 与科学性, 进而推动我国风力发电技术不断向前发展。

1 风力发电技术发展现状

是把风能转变为电能的技术。通过风力发电机实现, 利用风力带动风车叶片旋转, 再透过增速机将旋转的速度提 升, 来促使发电机发电。风力发电技术主要应用于多风地区, 特别是偏僻的山区以及昼夜温差较大的高山湖泊地区。 在冷热气流的碰撞与震动过程中, 转化成风力作用, 这种风力作用所蕴含的能量十分巨大, 能够为风力发电提供能量 ${ }^{[3]}$ 。 就目前我国的风力发电水平而言, 在部分地区风速达到 10 米/秒时, 仅需利用 50 台风力发电机发电 24 小时, 就能满 足我国的小县城一天的电能需求。当前, 我国的风力发电设备能够实现良好的电能转化与储存, 且电能运输损耗率较 低 ${ }^{[4]}$ 。但就我国目前的风力技术和规模而言, 暂时未实现风力资源的充分利用。特别是在部分风力资源丰富, 且较为贫 困的地区, 可能由于施工难度较大、技术存在局限性等问题, 难以充分利用风力资源, 导致资源白白浪费。2019 年, 我国新增风电并网容量达到 794 万千瓦, 增长态势十分可观。当前我国风电新增装机容量和累计装机容量已经长期位 居世界首位, 风力发电占据全部发电量的 $5 \%$, 风轮的直径也逐渐增大。由此可见, 我国风力发电已经取得一定的成就, 但还存在一些尚未解决的技术问题。

\section{2 当前我国风力发电技术发展主要面临的问题}

2. 1 风力发电控制系统灵敏性较低

在风力发电的控制过程中, 需要技术人员关注许多数据, 而传统的风力发电控制系统灵敏性相对较低, 难以有效 控制风力发电技术的有效应用, 使得整体发电工程的控制效果不佳 ${ }^{\left[{ }^{[}\right]}$。近年来, 由于风力发电控制系统的失误和技术水 平的不足, 造成了许多电力事故, 十分不利于风力发电工程的顺利实施。

\section{2 风电机组的安全性不高}

安全性是发电技术应用的关键问题, 由于我国当前风电技术的研究起步较晚, 风电技术的应用时间较短, 因此风 
力发电技术应用的安全性能并不高, 尤其在并网、输送、装机等方面, 还存在事故率较高的问题, 导致风力发电安全 隐患较多，难以保证技术人员的人身安全和身体健康。

\section{3 风力发电机电容量不足}

就目前而言, 我国的风力发电机的容量已经普遍达到一兆瓦以上, 但这一水平尚不能满足我国城市的用电需求, 随着我国经济的不断发展, 这一需求还将逐渐增加。当前, 美国已经开始研发电容量为十兆瓦的发电机, 由此可见我 国的发电机电容量还存在一定落后的情况, 因此在未来的风力发电技术研发过程中, 相关研究人员将不断提升风力发 电的最大电容量。

\section{3 我国风力发电技术发展趋势}

\section{1 提高风力发电机电容量}

随着我国科学技术水平的不断发展, 风力发电最大电容量很可能会在近几年达到五十兆瓦。提高风力发电机电容 量, 能够确保风力能源得到良好的转化和存储, 推动风力发电技术的发展, 充分提高我国的风能利用率, 使得风能发 电工程的经济效益大大提升 ${ }^{[6]}$ 。

\section{2 变浆距将成为发展主流}

提高风力发电技术水平的关键还在于改善风力发电设备。在实际的风能发电过程中, 当电网因风力不稳定而发生 故障, 需要进行紧急停机操作时, 风力发电设备应当能够通过改变风轮的浆距角使叶尖速比保持在最佳状态。进而提 高风力发电的安全性，优化停机策略，有效控制风力发电过程中的低电压穿越情况。

\section{3 风力资源的利用率提升}

由于海上的风力资源要远远大于陆地上的风力资源, 当前, 世界上风力发电技术较为发达的国家普遍由陆地风力 发电向海上风力发电转移, 充分利用起海上的风力资源 ${ }^{[7]}$ 。海上风力发电能够有效减少对土地资源的消耗, 提高风力资 源的利用率，推动节能减排工作的顺利进行。同时，我国海域辽阔、沿海风力发电建设资源丰富，因此，我国的风力 发电也将逐渐向利用海上风力的方向发展。针对海上的风力发电技术研究, 应当主要关注海上风力发电的安全性和稳 定性, 确保海上风力发电设备能够长期稳定完成发电任务。

\section{4 结合实际地区风力状况进行精细化技术设计}

在未来的风电技术发展过程中，相关技术研究人员将针对不同地区的气候情况采取精细化技术设计。例如我国的 新疆、甘肃、内蒙古地区属于干燥高原地区, 具有风速低、大风时间短、空气密度小的特点, 如果盲目使用高风速、 高功率的进口电风机, 就可能会出现发电效率严重偏低的现象。因此, 当地风电技术与设备应当针对低风速、低空气 密度进行设计, 提高风电机的发电率, 避免风能资源的浪费, 积极发展微风高效新型风电机, 以提高相应地区的风电 技术发展水平。

\section{5 引入现代化信息化技术}

随着现代化信息技术与科学技术的不断发展, 为了提高风力发电的可靠性与安全性, 我国的风力发电控制技术逐 渐向着现代化信息化的趋势发展。其中，自适应控制技术就是现代化信息化技术的产物，在风力发电控制系统中应用 自适应控制技术，使得控制系统能够有效把控发电设备的变化，自动报警并采取有效的控制措施。这不仅能够有效保 证风力发电的稳定性, 提高风力发电控制系统灵敏度, 还能确保风力发电的安全性, 弥补系统中相关控制技术的不足, 从整体上提升风力发电技术的科学性，提高风能的利用率，对风力发电工程的发展有积极的推动作用。

\section{4 结语}

风能是一种清洁的可再生能源, 风能的有效利用能够减少传统能源和不可再生能源的过度消耗, 因此大力发展风 力发电技术，对于我国节能减排政策的落实具有重要意义。在实际的风力发电技术应用过程中，工作人员应当注意结 合实际地区的风力状况进行精细化设计, 积极引入现代信息技术, 提高风力发电的科学性, 充分利用我国的风力资源, 推动我国风力发电技术登上新台阶。

\section{[参考文献]}

[1]鲁民, 李冰皓. 新能源风力发电系统中自适应控制技术的应用及未来前景探讨 [J]. 时代农机, 2020,47(06) : 81-82.

[2] 吴文凯, 赵寒涛. 基于磁悬浮技术的垂直轴风力发电单元的设计 [J]. 自动化技术与应用, 2019, 38(12) : 22-25.

[3] 刘潇.刍议风力发电控制系统中现代信息化控制技术的应用方法 [J].科技创新导报, 2019, 16 (35) : 14-16.

[4] 徐惠. 梁板结构䇝板型针栓组合件风力发电风机基础施工关键技术 [J]. 建筑技术开发, 2019,46(18): 111-112.

[5]柴向春,奎明玮. 基于风力发电技术发展现状以及行业发展分析 [J].中国新通信, 2018,20(21): 227.

[6] 陈璇. 基于 PLC 风力发电控制系统的设计技术研究 [J]. 科技资讯, 2017, 15(28): 51-53.

[7] 李林, 于惠钧, 闵婕, 田淑慧, 荣俊梅. 现代电力电子技术在风力发电中的研究进展与应用 $[\mathrm{J}]$. 电子元器件与信息技 术, 2017, 1 (01) : 75-80.

作者简介: 李晓明（1987.10.11-), 男, 民族: 汉, 籍贯: 沈阳, 单位: 辽宁龙源新能源发展有限公司, 职务: 运行 值班员, 职称: 助理工程师, 学历: 本科, 研究方向: 风电运维。 